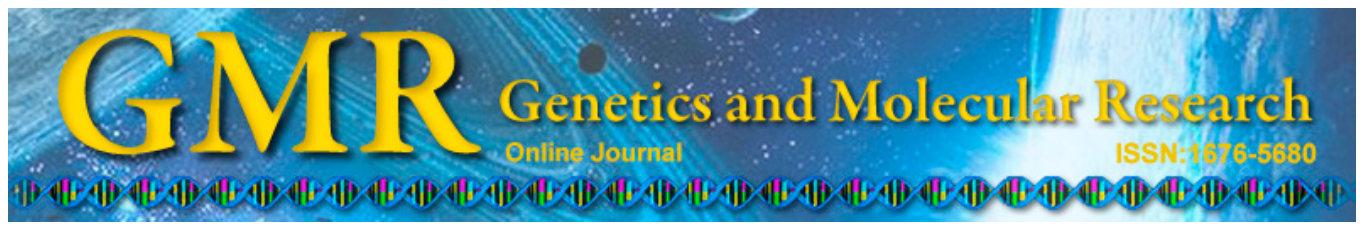

\title{
Changes to the migratory inhibitory factor, IL-17, and IL-10 levels in serum from chronic hepatitis $B$ patients and clinical significance following Baraclude ${ }^{\circledR}$ treatment
}

\author{
X.-H. Yu' ${ }^{1}$, J.-C. Zhang1, X.-Y. Li ${ }^{1}$ and T. Chen ${ }^{2}$ \\ ${ }^{1}$ Gastroenterology Department of the General Hospital of Lanzhou in the \\ Military District of Lanzhou, Lanzhou City, Gansu Province, China \\ ${ }^{2}$ Analysis Department of the General Hospital of Lanzhou in the Military \\ District of Lanzhou, Lanzhou City, Gansu Province, China \\ Corresponding author: X.-H. Yu \\ E-mail: yuxiaohui_yxh@163.com
}

Genet. Mol. Res. 14 (2): 3362-3369 (2015)

Received July 11, 2014

Accepted October 8, 2014

Published April 13, 2015

DOI http://dx.doi.org/10.4238/2015.April.13.16

\begin{abstract}
This study aimed to determine the relationship between changes in the serum levels of macrophage migratory inhibitory factor (MIF), interleukin (IL) 17, and IL-10 during chronic hepatitis B treatment via Baraclude ${ }^{\circledR}$ (Bristol-Meyers Squibb). Thirty-six patients with chronic hepatitis B and 24 healthy individuals were selected as the experimental and control groups, respectively, and the serum levels of MIF, IL-17, and IL-10 were measured during the period in which the experimental group was treated with oral Baraclude ${ }^{\circledR}$; meanwhile, the alanine aminotransferase (ALT), hepatitis B virus (HBV) DNA, and HBV marker (M) levels were measured in the experimental group. In the experimental group, the ALT and HBV-DNA levels began to exhibit obvious decreases in week 4, and the MIF and IL-17 levels exhibited obvious increases in week 4 followed by gradual decreases; however, the IL-10 level exhibited an obvious decrease in week 12 and then
\end{abstract}


increased gradually. These changes were significant when compared with the control group $(\mathrm{P}<0.05)$. In conclusion, Baraclude ${ }^{\circledR}$ treatment not only actively suppressed HBV but also indirectly balanced the MIF, IL-17, and IL-10 levels and reduced the liver inflammatory response.

Key words: Chronic Hepatitis; Migratory inhibitory factor; Baraclude $^{\circledR}$; IL-17; IL-10

\section{INTRODUCTION}

Hepatitis B virus (HBV) infection is a global health issue, and the chronic viral disease hepatitis type $\mathrm{B}$, which is caused by HBV infection, is an important disease that threatens human health. During the process of hepatitis type B development, various cytokines participate in the process of immunological incompetence, which is mediated by thymus-dependent lymphocytes and closely related to the HBV duplication and hepatic cell damage. Currently, nucleoside drugs are believed to effectively control HBV duplication, relieve or control the progress of viral hepatitis type $\mathrm{B}$, and impede the development of liver cirrhosis and the malignant transformation of hepatic cells. Of these agents, the representative drug Baraclude ${ }^{\circledR}$ (Bristol-Meyers Squibb, New York, NY, USA) is a strong antiviral drug that exhibits the characteristics of high efficiency and very low tolerance (De Clercq, 2013); this drug is widely used in antiviral therapy for hepatosis consequent to HBV infection. The present study evaluated the relationships of the serum levels of macrophage migration inhibitory factor (MIF), interleukin (IL) 17, and IL-10 with the HBV load and changes in liver function during the process of Baraclude ${ }^{\circledR}$-mediated treatment for chronic viral hepatitis type B in order to deeply understand whether Baraclude ${ }^{\circledR}$ acts to regulate immune function in the liver and relieve the liver inflammatory reaction while exerting its anti-HBV activity.

\section{MATERIAL AND METHODS}

\section{General information}

All cases were selected from inpatients and outpatients who were diagnosed from February 2012 to February 2013 according to the standard of the Viral Hepatitis Prevention Scheme (revised in December 2010) of the Gastroenterology Department of Lanzhou General Hospital of Lanzhou Military Region (Chinese Society of Hepatology and Chinese Society of Infectious Diseases, 2011). Thirty-six chronic viral hepatitis type B patients were randomly selected as the experimental group, including 26 males and 10 females ranging in age from 18 to 54 years with an average age of $33.03 \pm 4.21$ years; all patients exhibited hepatitis B serum antigen (HBsAg) positivity for $>6$ months and serum HBV-DNA levels $>2 \times 10^{4} \mathrm{IU} / \mathrm{mL}$. Additionally, in these patients, the serum alanine aminotransferase (ALT) levels continuously or discontinuously increased to $>2$ times the normal value limit. Twenty-four healthy individuals were selected as the control group, including 14 males and 10 females ranging in age from 22 to 45 years with an average age of $29.68 \pm 4.26$ years. None of the patients in either group had a history of hepatitis C, D, or G virus, human immunodeficiency virus, or Epstein-Barr virus infection. 


\section{Pharmacotherapy and clinical index detection}

The experimental group patients began taking oral Baraclude ${ }^{\circledR}(0.5 \mathrm{mg})$ once daily for 48 weeks beginning at the baseline time point (and later continued to receive pharmacotherapy). The HBV marker (HBV-M), HBV-DNA, and ALT levels were determined at the baseline and on the same weekday during weeks $4,12,24,36$, and 48 after therapy initiation. Both the ALT and HBV-M were detected via enzyme-linked immunosorbent assays, and HBV-DNA was detected via a reverse transcriptase PCR method.

\section{Detection of MIF, IL-17, and IL-10 in the peripheral blood}

Five $\mathrm{mL}$ of venous blood were drawn from each subject in the experimental and control groups at the baseline time point and on the same weekday in weeks 4, 12, 24, 36, and 48 after therapy initiation; $2 \mathrm{~mL}$ of serum were extracted from each blood sample after centrifugation and cryopreserved at $-20^{\circ} \mathrm{C}$ for further applications. The MIF, IL-17, and IL-10 detection kits were purchased from Santa Cruz Biotechnology (Santa Cruz, CA, USA) and were used according to the manufacturer specifications.

\section{Statistical methods}

The results are reported as means $\pm \mathrm{SE}$ (standard error) and analyzed using the $t$-test. The SPSS statistical software version 13.0 (SPSS Inc., Chicago, IL, USA) was used for the statistical analysis.

\section{RESULTS}

\section{Changes in the clinical index after oral Baraclude ${ }^{\circledR}$ administration}

After Baraclude ${ }^{\circledR}$ treatment, the levels of HBV-DNA in the sera of patients in the experimental group exhibited obvious decreases beginning in week 4; the lower HBV-DNA detection limit was approached in week 12 and achieved in week $36(<100 \mathrm{IU} / \mathrm{mL})$. Correspondingly, the ALT levels began to obviously decrease in week 4, approach the upper normal limit (40 IU/L) in week 12 , and reach the normal limit in week 36 . Regarding this serological transition, patients in the experimental group exhibited $\mathrm{HBsAg}$ positivity at the baseline; in week 4, 5 patients became HBsAg-negative, 1 of whom exhibited an $\mathrm{HBeAg}$ transition, and in week 48, 8 patients became HBsAg-negative, 4 of whom exhibited HBeAg transitions (Table 1 and Figures 1, 2, and 3).

\begin{tabular}{|c|c|c|c|}
\hline Time point & ALT (IU/L) & HBV-DNA (Ig) & HBsAg $(\mathrm{IU} / \mathrm{mL})$ \\
\hline Baseline & $182.06 \pm 13.68$ & $7.95 \pm 0.82$ & $1980.91 \pm 53.98$ \\
\hline Week 4 & $85.30 \pm 6.91^{\boldsymbol{\Lambda}}$ & $4.17 \pm 0.98^{\mathbf{A}}$ & $1023.02 \pm 41.72$ \\
\hline Week 12 & $39.49 \pm 7.08 *$ & $3.02 \pm 0.94 *$ & $624.38 \pm 33.57$ \\
\hline Week 24 & $29.15 \pm 5.32$ & $2.5 \pm 0.58$ & $403.15 \pm 28.48$ \\
\hline Week 36 & $24.26 \pm 4.78$ & $2.0 \pm 0.00$ & $201.32 \pm 23.34$ \\
\hline Week 48 & $18.41 \pm 4.05$ & $2.0 \pm 0.00$ & $92.26 \pm 15.17$ \\
\hline
\end{tabular}

$\triangle \mathrm{P}<0.05$ vs the baseline; $* \mathrm{P}<0.05$ vs week 4. 


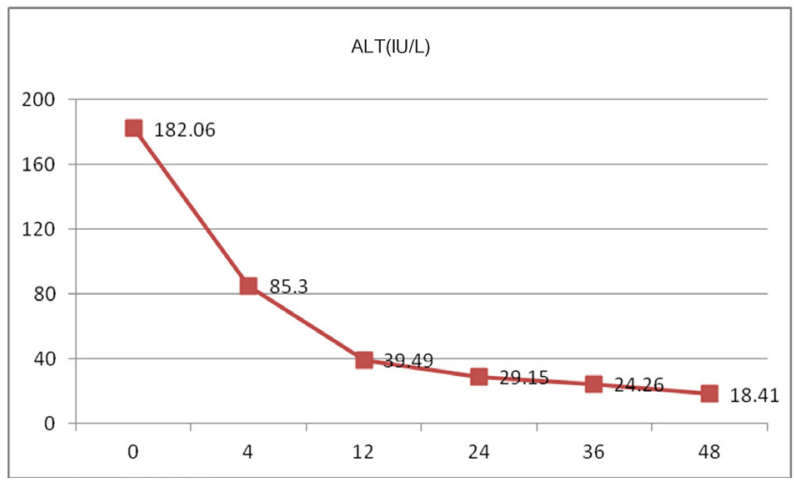

Figure 1. Changes in the alanine aminotransferase levels at each time point after oral Baraclude ${ }^{\circledR}$ treatment for chronic viral hepatitis type B. Data are reported as means \pm SE.

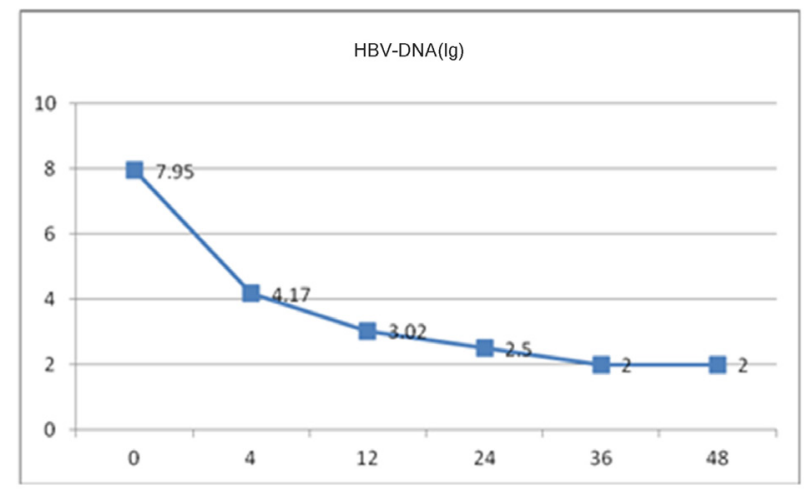

Figure 2. Changes in the hepatitis B virus DNA at each time point after oral Baraclude ${ }^{\circledR}$ treatment for chronic viral hepatitis type B. Data are reported as means \pm SE.

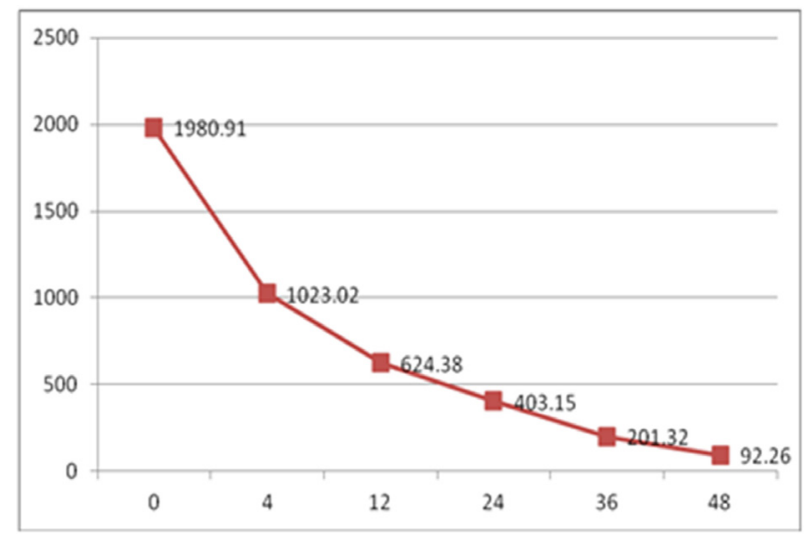

Figure 3. Changes in the HBsAg at each time point after oral Baraclude ${ }^{\circledR}$ treatment for chronic viral hepatitis type B. Data are reported as means $\pm \mathrm{SE}$. 


\section{Changes in the serum levels of MIF, IL-17, and IL-10 during the Baraclude ${ }^{\circledR}$ treatment period}

The levels of MIF and IL-17 in the sera of patients in the experimental group began to decrease gradually beginning in week 4 and decreased to the level of the control group by week 48 . The levels of IL-10 began to increase gradually beginning in week 4 and were similar to the level of the control group by week 48 (Table 2 and Figure 4).

\begin{tabular}{|c|c|c|c|}
\hline Time point & $\operatorname{MIF}(\mathrm{ng} / \mathrm{mL})$ & IL-17 (ng/mL) & $\mathrm{IL}-10(\mathrm{ng} / \mathrm{mL})$ \\
\hline \multicolumn{4}{|c|}{ Experimental group } \\
\hline Baseline & $94.28 \pm 13.47$ & $69.87 \pm 10.85$ & $102.88 \pm 20.74$ \\
\hline Week 4 & $75.36 \pm 7.83^{\mathbf{\Delta}}$ & $44.57 \pm 7.68^{\mathbf{4}}$ & $119.98 \pm 24.46^{\mathbf{\Delta}}$ \\
\hline Week 12 & $51.45 \pm 8.54^{*}$ & $23.16 \pm 9.64 *$ & $121.35 \pm 20.18^{*}$ \\
\hline Week 24 & $29.75 \pm 7.28$ & $16.45 \pm 8.28$ & $170.32 \pm 18.53$ \\
\hline Week 36 & $16.16 \pm 4.08$ & $10.09 \pm 6.32$ & $199.27 \pm 25.24$ \\
\hline Week 48 & $10.45 \pm 5.31^{\Delta}$ & $6.25 \pm 5.18^{\Delta}$ & $250.41 \pm 31.36^{\Delta}$ \\
\hline \multicolumn{4}{|c|}{ Control group } \\
\hline Baseline & $12.07 \pm 8.27$ & $6.7 \pm 5.94$ & $250.32 \pm 22.33$ \\
\hline Week 4 & $9.35 \pm 5.02$ & $8.49 \pm 7.08$ & $234.09 \pm 21.33$ \\
\hline Week 12 & $10.42 \pm 7.32$ & $8.45 \pm 6.60$ & $222.38 \pm 18.90$ \\
\hline Week 24 & $11.09 \pm 7.44$ & $7.22 \pm 5.29$ & $235.65 \pm 23.31$ \\
\hline Week 36 & $10.09 \pm 5.14$ & $8.11 \pm 7.13$ & $241.71 \pm 23.38$ \\
\hline Week 48 & $9.89 \pm 6.82$ & $6.11 \pm 6.10$ & $266.19 \pm 26.79$ \\
\hline
\end{tabular}

$\triangle \mathrm{P}<0.05$ vs the baseline; $* \mathrm{P}<0.05$ vs week $4 ; \mathrm{P}<0.05$ vs week $12 ;{ }^{\Delta} \mathrm{P}>0.05$ vs the control group.

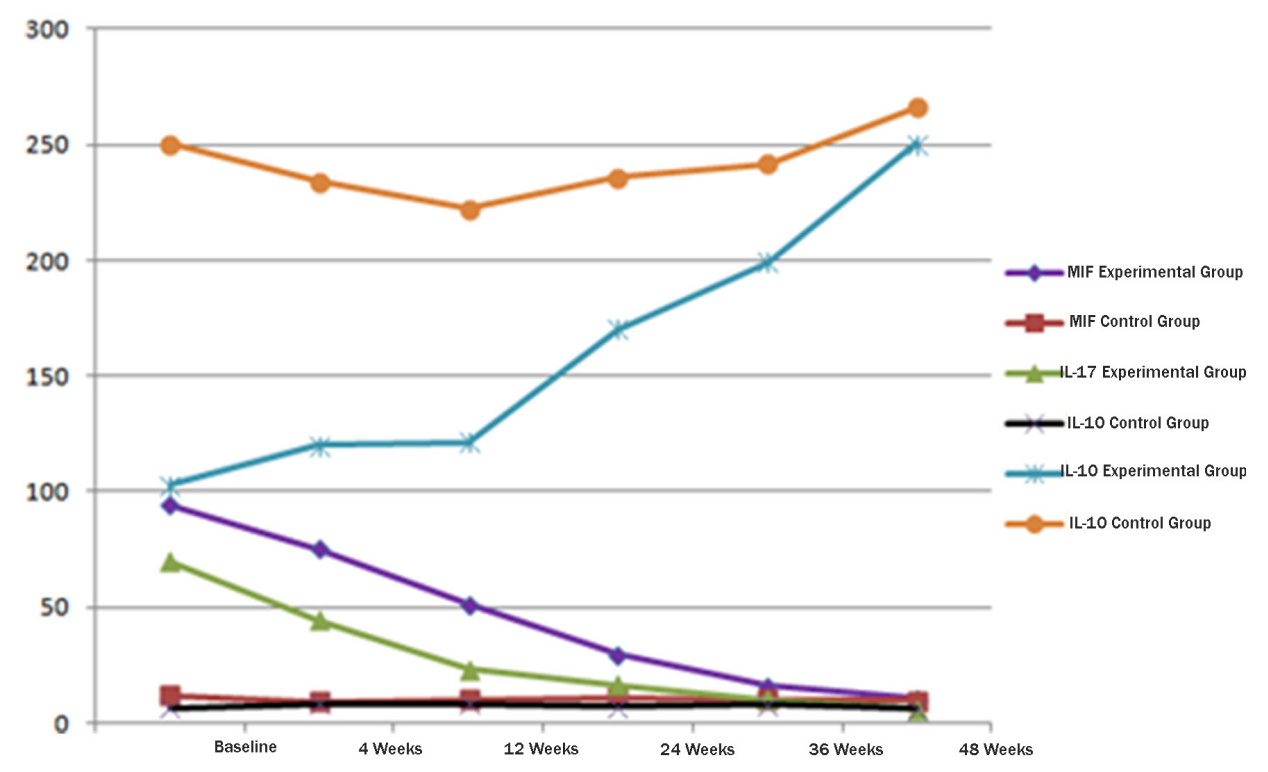

Figure 4. Changes in the serum levels of migration inhibitory factor, interleukin (IL) 17, and IL-10 during the course of oral Baraclude ${ }^{\mathbb{R}}$ treatment for chronic viral hepatitis type B. 


\section{DISCUSSION}

Baraclude $^{\circledR}$ is potent and optional guanine nucleoside analogue with prominent antiHBV activity and a very low tolerance, among other features. This agent is currently in wide use as an antiviral therapy for hepatosis consequent to HBV infection (Huang et al., 2013). Histology, biochemistry, and improvements in virology indicate the obvious therapeutic effects of Baraclude ${ }^{\circledR}$; however, less research has been conducted on the changes in the levels of various cytokines or relief from the inflammatory response to chronic viral hepatitis type B after achieving viral control with Baraclude ${ }^{\circledR}$. Many studies (Musil et al., 2011) have reported the participation of various cytokines in the chronic viral hepatitis type B disease course; these cytokines, which include MIF, IL-17, and IL-10, elicit a variety of biological functions such as adhesion, phagocytosis, anti-tumor activity, and nitric oxide production and would therefore play important roles in inflammatory responses. The research conducted by Heinrichs et al. (2011) revealed an important role for MIF in pathological liver damage; similarly, the results of our preliminary study (Yu et al., 2012) indicated the participation of MIF in the overall occurrence and development of viral hepatitis type B, liver cirrhosis, liver cancer, and other hepatopathies and that changes in the MIF levels were closely related to the extent of liver tissue damage. Miquel et al. (2013) reported that immune tolerance was broken following antiviral therapy with Baraclude ${ }^{\circledR}$ such that the level of MIF in the liver tissue was initially enhanced and then gradually reduced. Ismail et al. (2013) reported that hepatic cells secreted less MIF following the antiviral therapy with Baraclude ${ }^{\circledR}$, thus reducing the secretion of vascular endothelial growth factor, transforming growth factor, ILs, matrix metalloproteinases, and various other cytokines, relieving inflammation, and consequently reducing the malignant transformation of hepatic cells. These results demonstrated that MIF exerted dual functions that could promote the inflammation and malignant transformation. The elevated levels of inflammation and rate of malignant transformation were reduced after Baraclude ${ }^{\circledR}$ treatment. The findings of the present research were that in addition to the effective antiviral activity of Baraclude ${ }^{\circledR}$, the levels of MIF in the sera of patients in the experimental group gradually decreased and the ALT levels also gradually normalized, both of which clearly indicated that the liver damage inflicted by the proinflammatory cytokine MIF was closely related to the HBV load.

In a previous report (Zhang et al., 2010), IL-17 was found to play an important role in preventing extracellular bacterial infections and mediating chronic inflammation and autoimmunity. This cytokine was closely related to the occurrence of chronic viral hepatitis type B and it mainly acted at the intersection of the active and innate immune responses while also affecting innate immunity and host defense. The research findings of Wang et al. (2011) revealed that in HBV-induced liver tissue inflammation, IL-17 mainly acted by inducing infected hepatic cells and mobilizing neutrophils to release proinflammatory cytokines. Meanwhile, IL-17 acted to increase protease and proteolytic enzyme activity in neutrophils and could also stimulate the expression of IL-6 and tumor necrosis factor, which also played important roles in the inflammatory reactions in HBV-infected livers. In our clinical research, following antiviral therapy with Baraclude, the levels of IL-17 in the sera of patients in the experimental group began to gradually decrease in week 4; the ALT levels also gradually normalized, indicating that the IL-17 level decreased and liver inflammation was relieved along with the decrease in the HBV load after antiviral therapy.

The research conducted by Arnaud et al. (2008) revealed that IL-10 could control 
cytokine secretion from mononuclear macrophages and thymus-dependent lymphocytes under the condition that both antigens and antigen-presenting cells were present; specifically, IL-10 could reduce Th1 cytokine expression and influence HBV elimination and therefore acted to inhibit inflammation. Our findings revealed that the levels of IL-10 in the sera of patients in the experimental group began to gradually increase in week 4. However, Das et al. (2012) believed that the secretion of large amounts of IL-10 from hepatic cells would promote HBV elimination; accordingly, hepatic cells exposed to HBV infection and liver tissue damage might activate immune cells to release large amounts of proinflammatory cytokines, whereas cytokine-damaged hepatic cells might also release certain amounts of anti-inflammatory cytokines to protect the cells from proinflammatory cytokine damage via autocrine secretion. Our experimental results revealed that after oral Baraclude ${ }^{\circledR}$ administration, the levels of IL-10 in the sera of patients in the experimental group began to gradually increase and the levels of ALT gradually normalized, indicating that along with the reduced viral load, the infected hepatic cells secreted more IL-10, thus gradually relieving the liver inflammation.

By week 48, all patients in the experimental group had achieved serum virology transitions and some had achieved HBeAg transitions and normalized ALT levels, thus indicating the expected effects of Baraclude ${ }^{\mathbb{B}}$ treatment had been achieved; these findings also demonstrated significant changes in the immune statuses of patients in the experimental group relative to the baseline. One previous study (Tong et al., 2013) found that an excessively high HBV viral load might inhibit the immunoreactivity and cause immune tolerance; subsequent breaking of this tolerance would induce strong immunoreactions. In the current study, the levels of MIF and IL-17 in the sera of patients in the experimental group began to gradually decrease and the level of IL-10 began to gradually increase during week 4 after Baraclude ${ }^{\circledR}$ treatment initiation; the levels of anti-inflammatory and proinflammatory cytokines gradually reached a balance, which prevented extensive inflammation and hepatic cell necrosis. Another group (Luo et al., 2013) also believed that inflammatory response relief in the liver might be caused by the elimination of viral antigens consequent to the continuous Baraclude ${ }^{\circledR}$-mediated inhibition of viral replication. In addition, Fahrtash-Bahin et al. (2013) reported that the inflammatory cytokinemediated apoptosis eliminated HBV by eliminating the residual infected hepatic cells and that this comprised an important curative mechanism in patients with chronic viral hepatitis type B; however, the hypersecretion of MIF, IL-17, and other inflammatory cytokines might induce a strong immunoreaction and lead to $\mathrm{HBV}$-induced fulminant hepatic failure.

In conclusion, during the course of Baraclude ${ }^{\mathbb{B}}$ treatment for chronic viral hepatitis type B, the levels of MIF and IL-17 gradually declined and levels of IL-10 slowly increased in the patients' sera, and these levels approached those of the control group by week 48; in addition, the patients' HBV loads decrease, the ALT levels normalized, and some patients achieved HBeAg transition. Therefore, we believe that the changes observed in the serum

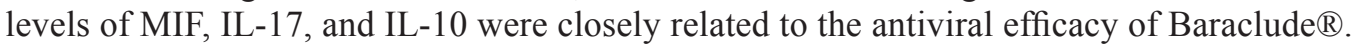
The ALT levels began to obviously decrease in week 4 and approached and reached the upper normal limit in weeks 12 and 36, respectively, indicating that the effective antiviral activity of Baraclude ${ }^{\circledR}$ could indirectly adjust the balance of related cytokines, restrict cytokineinduced damage to hepatic cells, and fully relieve the inflammatory reactions of hepatic cells, thus achieving the goal of treating chronic viral hepatitis type B. This mechanism requires further research. 


\section{ACKNOWLEDGMENTS}

Research supported by the Gansu Natural Science Foundation (\#0803RJZA059) and the Research Foundation for Medical Science and Public Health of Public Liberation Army (PLA) (\#CLJILJA02).

\section{REFERENCES}

Arnaud V, Li J, Wang Y, Fu X, et al. (2008). Regulatory role of interleukin-10 and interferon-gamma in severe hepatic central and peripheral fibrosis in humans infected with Schistosoma japonicum. J. Infect. Dis. 198: 418-426.

Chinese Society of Hepatology and Chinese Society of Infectious Diseases, Chinese Medical Association (2011). The guideline of prevention and treatment for chronic hepatitis B (2010 version). Zhonghua Ganzangbing Zazhi 19: 13-34.

Das A, Ellis G, Pallant C, Lopes AR, et al. (2012). IL-10-producing regulatory B cells in the pathogenesis of chronic hepatitis B virus infection. J. Immunol. 189: 3925-3935.

De Clercq E (2013). A cutting-edge view on the current state of antiviral drug development. Med. Res. Rev. Doi: 10.1002/ med.21281.

Fahrtash-Bahin F, Kariyawasam VC, Gray T, Byth K, et al. (2013). Australian tertiary care outcomes of entecavir monotherapy in treatment naive patients with chronic hepatitis B. World. J. Gastroenterol. 19: 721-726.

Heinrichs D, Knauel M, Offermanns C, Berres ML, et al. (2011). Macrophage migration inhibitory factor (MIF) exerts antifibrotic effects in experimental liver fibrosis via CD74. Proc. Natl. Acad. Sci. U. S. A. 108: 17444-17449.

Huang LH, Qiu YW, Hua HY, Niu XH, et al. (2013). The efficacy and safety of entecavir in patients with advanced schistosomiasis co-infected with hepatitis B virus. Int. J. Infect. Dis. 11: 1000-1016.

Ismail AM, Sharma OP, Kumar MS, Eapen CE, et al. (2013). Virological response and antiviral resistance mutations in chronic hepatitis B subjects experiencing entecavir therapy: an Indian subcontinent perspective. Antiviral Res. 98: 209-216.

Luo J, Li X, Wu Y, Lin G, et al. (2013). Efficacy of entecavir treatment for up to 5 years in nucleos(t)ide-naïve chronic hepatitis B patients in real life. Int. J. Med. Sci. 10: 427-433.

Miquel M, Núñez O, Trapero-Marugán M, Díaz-Sánchez A, et al. (2013). Efficacy and safety of entecavir and/or tenofovir in hepatitis B compensated and decompensated cirrhotic patients in clinical practice. Ann. Hepatol. 12: 205-212.

Musil R, Schwarz MJ, Riedel M, Dehning S, et al. (2011). Elevated macrophage migration inhibitory factor and decreased transforming growth factor-beta levels in major depression - no influence of celecoxib treatment. J. Affect. Disord. 134: $217-225$.

Tong MJ, Kowdley KV, Pan C, Hu KQ, et al. (2013). Improvement in liver histology among Asian patients with chronic hepatitis B after long-term treatment with entecavir. Liver Int. 33: 650-651.

Wang L, Chen S and Xu K (2011). IL-17 expression is correlated with hepatitis B-related liver diseases and fibrosis. Int. J. Mol. Med. 27: 385-392.

Yu XH, Duan HC and Wang W (2012). Serum levels of macrophage migration inhibitory factor, interleukin-17 and interleukin-10 in patients with HBV-related liver disease. Chin. J. Gastroenterol. Hepatol. 6: 560-563.

Zhang JY, Zhang Z, Lin F, Zhou ZS, et al. (2010). Interleukin-17-producing CD4(+) T cells increase with severity of liver damage in patients with chronic hepatitis B. Hepatology 51: 81-91. 